\title{
Prevalence of Colorectal Polyps: A Retrospective Study to Determine the Cut-Off Age for Screening
}

\author{
Rajeev Jayadevan ${ }^{1}$, Anithadevi T S ${ }^{2}$, Sandeep Sabu ${ }^{3}$. Ramakrishnan P. Venugopalan ${ }^{4}$ \\ ${ }^{1}$ Department of Gastroenterology, Sunrise Hospital, Kakkanad,Kochi,India \\ ${ }^{2}$ Department of Bio-statistics, Sunrise Hospital, Kakkanad, Kochi,India \\ ${ }^{3}$ Department of Gastroenterology, Sunrise Hospital, Kakkanad, Kochi,India \\ ${ }^{4}$ Department of Gastroenterology, Amrita Institute of Medical Sciences, Kochi,
}

Received: 19 November, 2015; Accepted: 12 April, 2016; Published: 17 May, 2016

*Corresponding author: Dr. Rajeev Jayadevan,Senior Consultant Gastroenterologist and Deputy Medical Director,Sunrise Hospital, Seaport-Airport Road, Kakkanad, Kochi,Pin: 682030, Kerala, India.Telephone: +91-984-7102221 Fax: +91-484-2428917; E-mail: rajeevjayadevan@icloud.com.

\begin{abstract}
Background: Data on the occurrence of colorectal polyps in the Indian subcontinent is scant. To study this, we conducted a retrospective analysis on 1604 consecutive patients who underwent colonoscopy.

Methods: The objective was to study the prevalence of colorectal polyps and adenomas among various age groups in the Indian subcontinent and to determine a cut-off age for screening for colon polyps. The parameters we considered were age, gender, indications and diagnosis. All polyps were removed colonoscopically by polypectomy, and the specimen was sent for histopathological examination.

Results: A total of 1604 colonoscopies were performed. The mean age was 47 years, $67.21 \%$ were above 40 years of age, and $32.79 \%$ were below 40 years. Polyps were detected in $11 \%$ of all patients and in $14.7 \%$ of patients over age 40 . Out of all polyps found, $41.8 \%$ were adenomatous polyps, $49.5 \%$ were hyperplasic polyps and $12.7 \%$ were others like inflammatory and hamartomatous polyps. Among the adenomas, $45.8 \%$ were found to be advanced adenomas. Prevalence of adenomatous polyps increased significantly above the age of 40 (P $<0.001$ ).

Conclusion: One out of six people in South India over age 40 had a polyp. The risk of occurrence of colorectal adenoma increased fivefold after age 40 .
\end{abstract}

Keywords: Colon cancer; Screening; Colonoscopy; Colon polyp

\section{Introduction}

Colorectal cancer is the third-leading cause of cancer deaths in the United States and United Kingdom [1]. The vast majority of colorectal cancers result from malignant transformation of benign polyp called adenoma [2]. This polyp-cancer sequence, which takes place over a span of several years, has been wellelucidated. It is believed that adenomatous polyps grow slowly over many years and malignant change eventually occurs. Adenomas greater than $10 \mathrm{~mm}$ in diameter are termed advanced adenomas. The risk of malignant change increases with increasing size of the adenoma, and is greater in advanced adenomas. The time span for the polyp to cancer transition process is believed to be an average of 10 years $[3,4]$. The detection and removal of polyps early in the polyp-cancer sequence is therefore of proven benefit in preventing colorectal cancer [5].

The prevalence of colorectal polyps in the western population is well-studied. However, data from the Indian sub-continent are limited. Thomas et al reported that polyps were found in $5.1 \%$ of colonoscopies in a South Indian population, and they were predominantly left-sided, at 90\% [6]. However, there were several limitations for that study as only $50 \%$ polyps identified were removed, and subjected to histopathological evaluation. In addition, colonoscopies were performed by different endoscopists including trainees.

We present our experience from 1604 colonoscopies from a tertiary care hospital in the city of Cochin in South India, that were performed by a single American Board-certified Gastroenterologist strictly adhering to ASGE's (American Society for Gastrointestinal Endoscopy) guidelines for lower GI examination [7]. Some of the quality metrics we followed included monitored withdrawal time, standardized bowel preparation, and all procedures being done under conscious IV sedation that allowed for adequate visualization of the entire colon. The endoscopist had 8 years' experience in high-volume endoscopy centers in the Northeastern United States prior to practicing gastroenterology in India. We therefore believe that this study will more accurately represent the pattern of colorectal polyps in a southern Indian population, and the data generated can be compared head-to-head with Western studies.

\section{Materials and Methods}

This is a retrospective study conducted on 1604 consecutive patients who underwent colonoscopy at Sunrise Hospital Cochin from April 2009 to April 2014. Patients with Inflammatory Bowel Disease (IBD) or colorectal cancer were excluded because these patients have a higher prevalence of polyps, and often underwent 
colonoscopy with an already established diagnosis, which could skew our findings towards higher prevalence of polyps. Patients of non-Indian origin were also excluded from the study. The parameters we considered were age, gender, indications and diagnosis. Indications for the procedure included blood in stool, to exclude colo-rectal cancer prior to haemorrhoidectomy, change in bowel habits, abnormal radiographic findings, lower abdominal pain and screening for polyps in patients with family history of colon cancer.

Colonoscopy is performed using Olympus CF HQ 190 L. Successful cecal intubation is achieved and the cecum is photographed. Meticulous examination is carried out during withdrawal of the colonoscope. In addition to being a diagnostic tool, colonoscopy can also be a therapeutic procedure to perform hemostasis, resection and ablation of benign and malignant disease. When a polyp is detected, its morphology and location are recorded. Polypectomy is then performed. The specimen is deposited in a labeled bottle with the site noted. The same protocol is repeated for each polyp and for each colonoscopy. The specimen bottles are sent to pathology department for histopathological evaluation.

The patient comes to the colonoscopy suite with a clean bowel after a bowel preparation which included four bisacodyl tablets and $2 \mathrm{~L}$ of polyethylene glycol (PEG)-based electrolyte solution. The preparation was administered after the patient was on a clear liquid diet for 6 hours, according to printed instructions that were also discussed in person by a trained nurse. Most of the patients took their bowel preparation at home, while a few were administered in hospitalized patients. The patient then gets assessed by a nurse for the general condition.

All procedures are done under IV sedation after informed consent specific for the procedure. The sedation was given under the supervision of the doctor. Our choice of medications included Midazolam and Fentanyl administered intravenously in incremental doses, with close monitoring of vital signs and oxygen saturation. During the procedure, the patient will be conscious and will be able to co-operate with verbal instructions.

In the recovery period, the patient is monitored for vital signs and general condition. Once found stable, the patient is discharged. Typically, a patient who comes in for a colonoscopy procedure can leave the endoscopy suite within 1 hour.

\section{Statistical Analysis}

There were 1604 patients who underwent colonoscopy. The subjects were classified into 5 groups, age under $30 \mathrm{yrs}, 30$ 40yrs, 40-50yrs, 50-60yrs and 60yrs and above, for studying the variation of the occurrence of polyps according to age. Descriptive statistics were used to find the prevalence of polyps and screening results. If more than one polyp was found in a patient, it was counted only as one for calculating prevalence. If both adenoma and hyperplastic polyp were found in one patient, adenoma was counted ahead of the hyperplastic polyp, in order to determine the true prevalence of adenoma. Some polyps, after removal, were found to be normal prolapsed colonic mucosa on histopathological examination. These were excluded from our analysis. Cylindrical diagram was used to represent the prevalence of polyps in different age groups. The difference in occurrence of pre-cancerous polyps were calculated by independent sample $t$ test, $p$-value $<0.01$. Distribution of adenomatous polyps was presented graphically using dough-nut diagram. All statistical analyses were carried out using Statistical Package for Social Sciences (SPSS) version 19.1 and Microsoft Office Excel 2007.

\section{Results}

A total of 1604 colonoscopies were performed by a single gastroenterologist at Sunrise hospital, Kakkanad, Cochin, of which 172 patients had colon polyps. The mean age was 47 years (range 14 to 90 years). In the study population, $67.21 \%$ were above 40 years of age, whereas, $32.79 \%$ were below 40 years. Polyps were detected in $11 \%$ of all patients and in $14.7 \%$ of patients over age 40 . Out of all polyps found, 72 (41.8\%) were adenomatous polyps, 85 (49.5\%) were hyperplastic polyps and 15 (12.69\%) were others like inflammatory and haemartomatous polyps (Table 1). Out of the population screened, family history of polyps was seen in $47(2.93 \%)$ patients but only 6 were diagnosed with polyps. True screening colonoscopies (in asymptomatic patients for screening purpose only) were done in 246 (15.33\%) patients, out of these 30 (12.19\%) were diagnosed with polyps.

Polyps were found in $2.3 \%$ patients in the age group below 30 years and $5.8 \%$ in the $30-40$ years group. Above the age of 40 , there was a significant increase in the prevalence of polyps: $23.8 \%$ in $40-50$ age group, $32.6 \%$ in $50-60$ and $35.5 \%$ in 60 and above. The age-wise distribution of adenomas were as follows: $0.6 \%$ in the below 30 age group, $1.7 \%$ in $30-40,8.7 \%$ in $40-50$, $9.9 \%$ in $50-60$ and $20.9 \%$ in 60 and above. These results indicate a higher risk of precancerous (adenomatous) polyps above the age of 40 (Figure 1).

Out of all the adenomas found, $45.83 \%$ were advanced adenomas (Table 2). The majority of adenomatous polyps were found in the left colon (70.83\%) compared to the right colon $(29.17 \%)$ (Figure 2). Prevalence of adenomatous polyps

Table 1: Baseline characteristics of the data.

\begin{tabular}{|c|c|}
\hline Characteristics & Frequency (\%) \\
\hline \multicolumn{2}{|l|}{ Age } \\
\hline Below 30 & $214(13.34)$ \\
\hline $30-40$ & $312(19.45)$ \\
\hline $40-50$ & 384 (23.94) \\
\hline $50-60$ & 335 (20.89) \\
\hline 60 and above & 359 (22.38) \\
\hline \multicolumn{2}{|l|}{ Polyps } \\
\hline Adenomatous & $72(41.8)$ \\
\hline Hyper plastics & $85(49.5)$ \\
\hline Others & $15(8.7)$ \\
\hline
\end{tabular}




\section{Occurence of polyps}

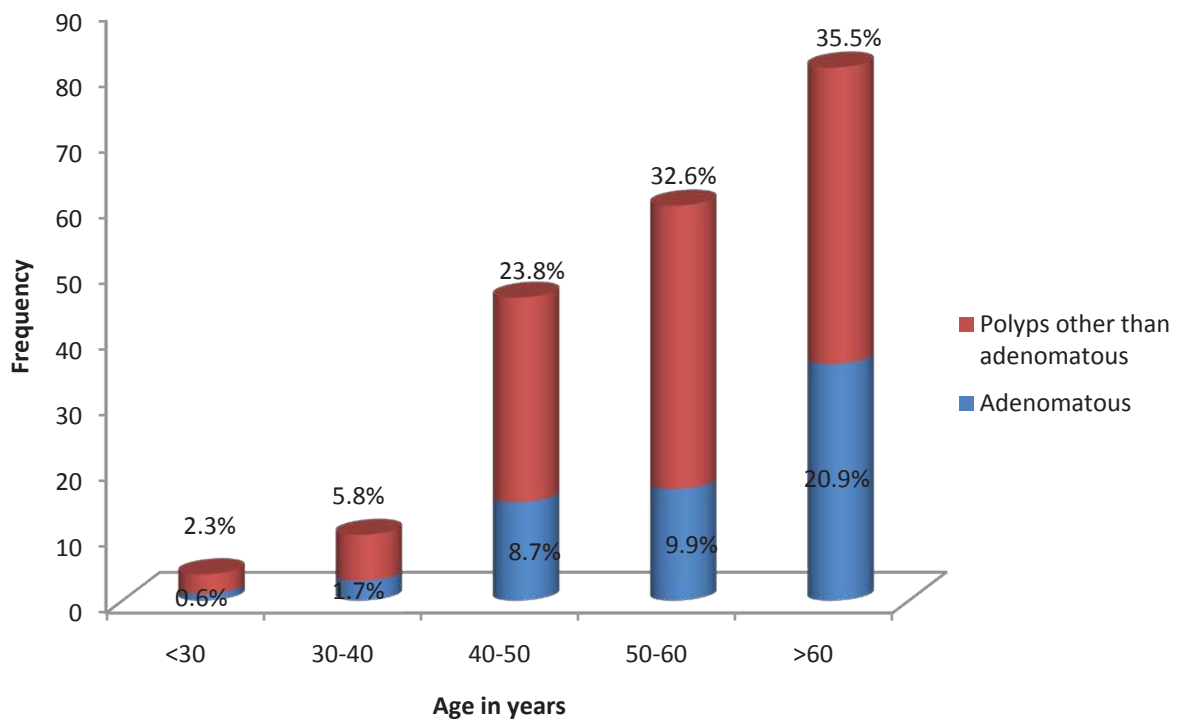

Figure 1: Occurrence of polyps according to age.

Table 2: Distribution of Adenomas.

\begin{tabular}{|c|c|c|c|}
\hline Location & $\begin{array}{c}\text { Advanced } \\
\text { Adenomatous } \\
(>\mathbf{1 0 m m})\end{array}$ & $\begin{array}{c}\text { Non- Advanced } \\
\text { Adenomatous } \\
\text { (<10mm) }\end{array}$ & Total \\
\hline Rectum & 13 & 9 & 22 \\
Sigmoid Colon & 8 & 9 & 17 \\
Ascending Colon & 2 & 3 & 11 \\
Descending Colon & 3 & 6 & 6 \\
Transverse Colon & 6 & 3 & 12 \\
Cecum & 1 & 3 & 4 \\
\hline
\end{tabular}

increased significantly above the age of 40 (Independent sample $\mathrm{t}$-test, $(\mathrm{t}=4.55, \mathrm{P}<0.001)$ ) (Table 3 ). Our findings show that there is a five-fold increase in the risk of adenoma over age 40 .

\section{Discussion}

Our study highlights a major finding, that there is a significant (five-fold) increase in the prevalence of colon polyps over age 40. After careful statistical evaluation of various cut-off age limits for the occurrence of colon polyps, we found that the significant spike in the incidence of polyp was at age 40 . This observation will have an impact on selecting the age cut-off for the appropriate screening colonoscopy for colorectal cancer in India, a topic that was debated in 2008 by the Asia Pacific colorectal cancer working group for colorectal cancer screening [8]. Yearly fecal occult blood testing, flexible sigmoidectomy and colonoscopy done as screening have each been proven to reduce long-term colorectal cancer mortality in the western hemisphere $[9,10,11,12,13]$.

At present there is a prevailing opinion that colon polyps and colorectal cancer are uncommon in India $[8,14]$. Unfortunately, there are insufficient data to confirm or refute this opinion.
The existing colon cancer data from India are patchy and heterogeneous, much of which is obtained from death registries which frequently do not list all the existing co-morbid conditions in a particular patient, leading to under-reporting of colorectal cancer [15]. Besides, colonoscopy was not widely available at the time of these earlier studies, leading to falsely low estimates of polyps and colorectal cancer [1]. The apparent preponderance of rectal and left-sided cancers reported earlier in India $[6,14]$ could be explained by incomplete or partial examination of the colon, and an over-dependence on bedside proctoscopies or sigmoidoscopies as opposed to a dedicated colonoscopy performed under optimal conditions by trained medical gastroenterologist.

In contrast to the United States of America or the UK, screening colonoscopy for asymptomatic individuals is not yet widely practiced in India [16]. Our study reports the occurrence of incidental colon polyps among patients who underwent colonoscopy for symptoms not directly caused by their polyps. Patients with known colorectal cancer and Inflammatory Bowel Diseases were excluded from the study, as several of these patients were referred with a preexisting diagnosis, and could 


\section{Location of adenomatous polyps}

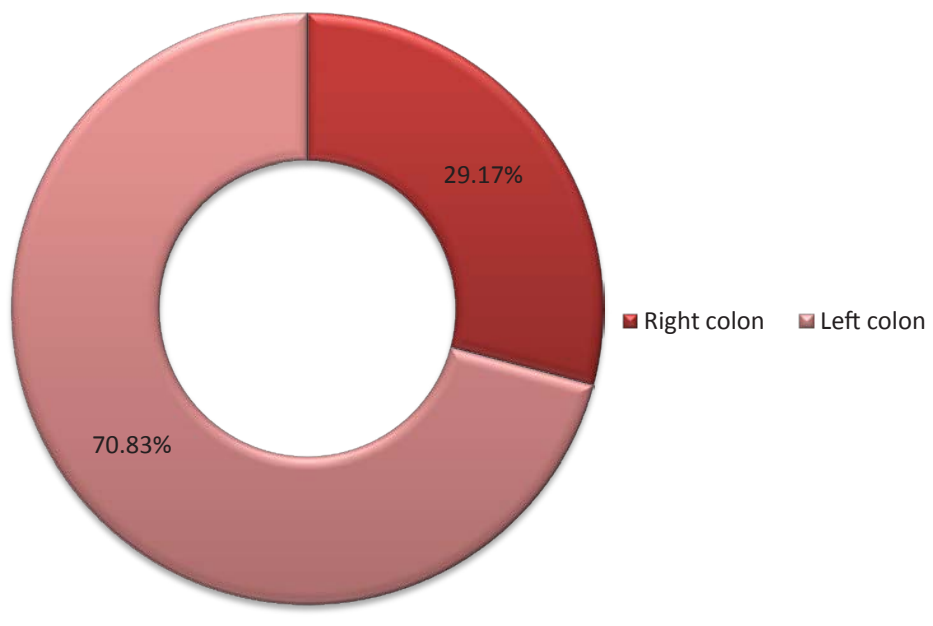

Figure 2: Distribution of Adenomatous polyps.

Table 3: Distribution of Adenomatous polyps according to age.

\begin{tabular}{|c|c|c|c|c|}
\hline Age in years & N & $\begin{array}{c}\text { Number of adenomatous } \\
\text { polyps }\end{array}$ & t value & P-Value \\
\hline Less than 40 & 526 & 4 & 4.55 & $<0.001$ \\
\hline More than 40 & 1078 & 68 & (Highly significant) \\
\hline
\end{tabular}

N: Total population which belongs to each age group.

potentially skew the observations of this study. Therefore, the findings may be considered almost equivalent to a screening of the general population.

The most common precursor of colorectal cancer is an adenoma [17]. It has been shown that screening asymptomatic patients for adenomas reduces long-term mortality from colorectal cancer [18]. While not all adenomas grow in to cancer, advanced adenomas (defined as adenomas $>10 \mathrm{~mm}$ diameter) are at highest risk of malignant transformation.

In our study, polyps were found in $14.7 \%$ of patients over age 40 , of which $41.8 \%$ were adenomatous polyps. Even in the relatively young $40-50$ age group, $8.7 \%$ patients had adenomas. Out of the adenomas found, 45.8\% (33/72) were advanced adenomas. These findings correlate with anecdotal reports of increasing colorectal cancer in India $[19,20]$. In our study, the ratio of left to right-sided adenomas was 70:30, which correlates with the findings of Peedicayil MC et al who found that $74 \%$ colorectal cancers in South India were left-sided [14]. The lower age of onset of colon adenomas found in our study also correlates well with the findings of Peedicayil MC, who reported that $12.7 \%$ of colorectal cancers in South India were below the age of 40 years [14].

Our finding that colorectal polyps are common in India, when coupled with reports of increasing incidence of colorectal cancer in India in younger patients by other authors, raises an important question regarding the need for screening colonoscopy in the general population in India - a practice yet to become standard of care in the subcontinent.

One of the limitations of our study is that it is technically not a screening study of the general population. However, we do believe that the vast majority of the polyps found in our study were incidental, and therefore the result can be extrapolated to that of a screening study. Although we excluded overt colorectal cancer and inflammatory bowel disease from our study, finding blood in stool (one of our indications for performing a colonoscopy) in some patients could still have been from a large polyp, leading to some selection bias. It should be noted, however, that bleeding is not a common symptom with colon polyps. Besides, a stringent screening study among asymptomatic persons cannot be carried out in India where it is not yet a widely accepted practice.

In contrast to our study, most colonoscopies performed in India are without sedation. The resulting patient discomfort could potentially impair the endoscopist's ability to examine the entire colon in sufficient detail. For instance, the patient's discomfort might prompt the endoscopist to insufflate less air and also to speed up the withdrawal, leading to lower adenoma detection rate, particularly in the right colon. All of our patients received IV Fentanyl and Midazolam, and were systematically monitored for pain control using an analog pain scale.

To our knowledge, this study is perhaps the first to generate 
high quality data on the true incidence of colorectal adenoma as well as other types of colon polyps in India through standardized colonoscopic examination protocols. In our study, 30\% adenomas were identified in the right colon, a higher number that reported by other Indian studies [6]. This may be explained by strict adherence to the standards of colonoscopic examinations including standardized bowel preparation and self-monitoring of cecum to rectum withdrawal time, a parameter that enhances polyp detection rates [21] and helps prevent missing of rightsided lesions [22]. Our cecum-to-rectum withdrawal time was estimated with the help of the time display in the computer. The average time taken for the withdrawal of the scope from cecumto-rectum was 6 minutes per case which was in accordance with ASGE's published standard ${ }^{[7]}$. We believe that our data can therefore be used for head-to-head comparison with similar studies done in western populations.

\section{Conclusion}

One out of six people in South India over age 40 had a polyp. The risk of occurrence of colorectal adenoma increased five-fold after age 40 .

\section{Acknowledgement}

- Dr Rajeev Jayadevan: Performed colonoscopies, designed the study and Manuscript preparation.

- Anithadevi T.S: Statistical analysis and review of literature

- Sandheep Sabu: Assisted the procedure, Data collection and compilation

- Ramakrishnan P. Venugopalan: Expert guidance and help with analysis/interpretation of data

\section{References}

1. Fatima A. Haggar, Robin P. Boushey. Colorectal Cancer Epidemiology: Incidence, Mortality, Survival, and Risk Factors. Clin Colon Rectal Surg 2009;22(4):191-197. doi: 10.1055/s-0029-1242458.

2. Cannon-Albright LA, Skolnick MH, Bishop DT, Lee RG, Burt RW Common Inheritance of Susceptibility to Colonic Adenomatous Polyps and Associated Colorectal Cancers. N Engl J Med. 1988;319(9):533537.

3. Noffsinger AE. Serrated polyps and colorectal cancer: new pathway to malignancy. Ann Rev Pathol. 2009;4:343-364. doi: 10.1146/annurev. pathol.4.110807.092317.

4. Levine JS, Ahnen DJ. Adenomatous polyps of the colon. N Engl J Med. 2006;355:2551-2557.

5. Bernard Levin, David A. Lieberman, Beth McFarland, Kimberly S. Andrews et al Screening and Surveillance for the Early Detection of Colorectal Cancer and Adenomatous Polyps, 2008: A Joint Guideline From the American Cancer Society, the US Multi-Society Task Force on Colorectal Cancer, and the American College of Radiology. Gastroenterology; Volume 134, Issue 5, Pages 1570-1595, May 2008.

6. Tony J, Harish K, Ramachandran T M, Thomas V. Profile of colonic polyps in a southern Indian population. Indian J Gastroenterol. 2007;26(3):127-129.

7. Sedlack RE, Shami VM, Adler DG, Coyle WJ, DeGregorio B, Dua KS, et al.
Colonoscopy core curriculum. Gastrointest Endosc. 2012;76(3):48290. doi: 10.1016/j.gie.2012.04.438.

8. Sung JJ, Lau JY, Young GP, Sano Y, Chiu HM, Byeon JS, et al. Asia Pacific consensus recommendations for colorectal cancer screening. Gut. 2008;57(8):1166-1176. doi:10.1136/gut.2007.146316.

9. Reiko Nishihara, Kana Wu, Paul Lochhead, Teppei Morikawa, Xiaoyun Liao, Zhi Rong Qian, et al. Long-Term Colorectal-Cancer Incidence and Mortality after Lower Endoscopy. N Engl J Med. 2013;369:1095-1105. doi: 10.1056/NEJMoa1301969.

10. Shaukat A, Mongin SJ, Geisser MS, Lederle FA, Bond JH, Mandel JS, et al. Long-Term Mortality after Screening for Colorectal Cancer. N Engl J Med. 2013;369(12):1106-1114. doi: 10.1056/NEJMoa1300720.

11. Douglas K. Rex. Colonoscopy Works!. N Engl J Med. 2013.

12. Douglas K. Rex, reviewing Hernandez LV. Adenoma Detection Rates Are Increasing in U.S. Ambulatory Surgery Centers. Gastrointest Endosc. 2014

13. Douglas K. Rex, reviewing Holme $\emptyset$.A Fourth Randomized, Controlled Trial of Flexible Sigmoidoscopy Screening. JAMA. 2014;312:606.

14. Peedikayil MC, Nair P, Seena SM, Radhakrishnan L, Sadasivan S, Naryanan VA, et al. Colorectal cancer distribution in 220 Indian patients undergoing colonoscopy. Indian J Gastroenterol. 2009; 28(6):212-5. doi: 10.1007/s12664-009-0087-z. Epub 2010.

15. Pathy S, Lambert R, Sauvaget C, Sankaranarayanan R. The incidence and survival rates of colorectal cancer in India remain low compared with rising rates in East Asia. Dis Colon Rectum. 2012; 55 (8):900-6. doi: 10.1097/DCR.0b013e31825afc4e.

16. Lieberman DA, Weiss DG, Bond JH, Ahnen DJ, Garewal H, Chejfec G.: Use of colonoscopy to screen asymptomatic adults for colorectal cancer. Veterans Affairs Cooperative Study Group 380. N Engl J Med.2000;343(3):162-168.

17. Takayama T, Katsuki S, Takahashi Y, Ohi M, Nojiri S, Sakamaki S et al. Aberrant Crypt Foci of the Colon as Precursors of Adenoma and Cancer. NEngl J Med. 1998;339(18):1277-1284. DOI: 10.1056/ NEJM199810293391803.

18.Zauber AG, Winawer SJ, O'Brien MJ, Lansdorp-Vogelaar I, van Ballegooijen $\mathrm{M}$, et al. Colonoscopic Polypectomy and LongTerm Prevention of Colorectal-Cancer Deaths. N Engl J Med. 2012;366(8):687-696.doi: 10.1056/NEJMoa1100370.

19. Barreto SG, Chaubal GN, TaloleS, DeSouza A, Suradkar K, GaikwadV, etal. Rectal cancer in young Indians--are these cancers different compared to their older counterparts?. Indian J Gastroenterol. 2014;33(2):146150. doi: 10.1007/s12664-013-0396-0.

20.Yeole BB. Trends in cancer incidence in oesophagus, stomach, colon, rectum and liver in males in India. Asian Pac J Cancer Prev. 2008;9(1):97-100

21. Barclay RL, Vicari JJ, Doughty AS, Johanson JF, Greenlaw RL. Colonoscopic withdrawal times and adenoma detection during screening colonoscopy. N Engl J Med. 2006;355(24):2533-41.

22. Rex DK, Bond JH, Winawer S, Levin TR, Burt RW, Johnson DA, et al. Quality in the technical performance of colonoscopy and the continuous quality improvement process for colonoscopy: recommendations of the U.S. Multi-Society Task Force on Colorectal Cancer. Am J Gastroenterol. 2002;97(6):1296-308. 